\title{
Doubt about effectiveness of lung metastasectomy for sarcoma
}

\author{
Tom Treasure, MD, MS, FRCS, FRCP, ${ }^{\mathrm{a}}$ and Fergus Macbeth, MA, DM, FRCR, FRCP(Glas), \\ FRCP(Lon), MBA $^{\mathrm{b}}$
}

See related article on pages $85-92$.

In this issue of the Journal in a thorough retrospective study of 155 patients who underwent lung metastasectomy for sarcoma from 1994 to 2010, Lin and colleagues ${ }^{1}$ conclude, "Future randomized prospective studies are warranted, particularly in patients with a poor risk profile, to define whether any benefit is derived from lung metastasectomy compared with other local therapies or no resection." This is a strong and very welcome statement. Randomized, controlled trials (RCTs) of metastasectomy are needed, and not just for those with "a poor risk profile." 2

Treatments should be of proven benefit. The greater is their potential for harm and the more costly they are, the more society is justified in challenging doctors and asking for proof. Surgery for advanced cancer is an area of practice where good evidence is scarce. RCTs of surgical interventions are difficult to design and harder to recruit to. When there is a close mechanistic and temporal relationship between surgery and a beneficial outcome, surgeons can perhaps see the signal amongst the noise, ${ }^{3,4}$ but pulmonary metastasectomy for sarcoma is different. Pathologic heterogeneity, multiple other treatments given after the surgery, and careful case selection are all possible confounders. Crucially, the long time lapse between the procedure and the observed effect means that any causal link has to be very uncertain. Lin and colleagues ${ }^{1}$ recognize this, writing, "In the absence of control (nonoperative) data, quantifying the difference in survival among patients who have undergone metastasectomy and attributing it to surgical resection may not be accurate because there is a selection bias for lung metastasectomy."

Randomization may be difficult, although it is possible. The uncertainty has first to be acknowledged, however, and only then can doubt be put to the test. Radical mastectomy was the standard of care for breast cancer for

\footnotetext{
From the Clinical Operational Research Unit, ${ }^{a}$ University College London, London, United Kingdom; and the Wales Cancer Trials Unit, ${ }^{\mathrm{b}}$ Cardiff University, Cardiff, United Kingdom.

Disclosures: Authors have nothing to disclose with regard to commercial support.

Received for publication Sept 20, 2014; accepted for publication Sept 21, 2014; available ahead of print Oct 18, 2014.

Address for reprints: Tom Treasure, MD, MS, FRCS, FRCP, Mathematics: Clinical Operational Research Unit, University College London, Falcon Farm, Ashford Rd, Badlesmere, Kent ME13 0NZ, United Kingdom (E-mail: tom.treasure@ gmail.com).

J Thorac Cardiovasc Surg 2015;149:93-4

$0022-5223 / \$ 36.00$

Copyright $(2015$ by The American Association for Thoracic Surgery http://dx.doi.org/10.1016/j.jtcvs.2014.09.073
}

80 years, ${ }^{5}$ and when cancer recurred the question arose in surgeons' minds, "Was I radical enough?". Doubts about effectiveness were set out by Fisher ${ }^{6}$ in a 50-page treatise in 1970. Radical mastectomy was already waning during the 1970 s, ${ }^{7}$ and in 1981 RCT findings allowed doctors to advise their patients that this mutilating surgery was not in their best interests. ${ }^{8}$ After the first reports of extirpative surgery for malignant pleural mesothelioma, ${ }^{9}$ its effectiveness was widely questioned. Nearly 40 years later, patients with mesothelioma can now be spared radical surgery because of the evidence from 2 RCTs. ${ }^{10}$

In this study of lung metastasectomy for sarcoma, most of the patients were free of symptoms (120/155), and Lin and colleagues $^{1}$ do not claim that the procedure improves symptoms. There is absolutely no information, however, on the effects of lung metastasectomy on lung function. A systematic review of the topic could also find no evidence that respiratory function or other patient-reported outcomes had ever been measured and so could not comment on palliative benefit. ${ }^{11}$ Indeed, a common reason for calling a halt to repeated resections is that patients run out of lung capacity and cannot tolerate any more surgery. These patients often have had many treatments and may suffer a lot; it also costs them a lot. ${ }^{12}$ Clearly, the finding of a solitary pulmonary metastasis in an otherwise symptom-free patient, more common now that routine computed tomographic imaging is part of follow-up, will cause understandable anxiety for the patient and prompt a desire among the clinical team to "do something." But is it right to subject patients to an invasive procedure simply to allay those concerns in the absence of robust evidence of effectiveness?

The important question is therefore survival difference. In 1980, the effectiveness of pulmonary metastasectomy was first questioned by Åberg and colleagues ${ }^{13}$ in a small but carefully done study. Åberg ${ }^{14}$ tackled the subject again some years later. In a large body of literature consisting entirely of observational surgical follow-up studies, the doubters are rarely cited. ${ }^{15}$

In the current article of Lin and colleagues, ${ }^{1}$ there are no control data, no description of a reference population, nor any denominator. Thus, as they themselves state, no reliable inferences can be drawn about a survival benefit from resection. Favorable histologic type, the number of metastases, and duration of survival before metastasectomy are all prognostic factors, but they are not predictors of effectiveness. ${ }^{16}$ As these are very reasonable factors for determining patient selection, it is impossible to separate out the effect of selection on survival after surgery. ${ }^{17}$ Another 
way of thinking about it, for patients having sequential treatments, is that the patient needs to be alive to have the next treatment, which might be confused with the belief that the patient is alive because of the previous treatment. ${ }^{18}$

If it is indeed the considered view of the 16 authors who constitute the group of Lin and colleagues ${ }^{1}$ that an RCT is the next appropriate study, then surely we must all work toward that goal. As we said of an equally difficult thoracic surgical question, randomized trials in surgery for mesothelioma, "Let's walk the talk." 19

\section{References}

1. Lin AY, Kotova S, Yanagawa J, Elbuluk O, Wang G, Kar N, et al. Risk stratification of pulmonary metastasectomy patients with soft tissue and bone sarcomas. J Thorac Cardiovasc Surg. 2015;149:85-92.

2. Treasure T, Utley M. Surgical removal of asymptomatic pulmonary metastases: time for better evidence. BMJ. 2013;346:f824.

3. Glasziou P, Chalmers I, Rawlins M, McCulloch P. When are randomised trials unnecessary? Picking signal from noise. BMJ. 2007;334:349-51.

4. Fiorentino F, Treasure T. Pulmonary metastasectomy for colorectal cancer: making the case for a randomized controlled trial in the zone of uncertainty. J Thorac Cardiovasc Surg. 2013;146:748-52.

5. Berwick DM. The science of improvement. JAMA. 2008;299:1182-4.

6. Fisher B. The surgical dilemma in the primary therapy of invasive breast cancer: a critical appraisal. Curr Probl Surg. 1970;7:1-53.

7. Ellis H. If I had... If my wife had cancer of the breast. Br Med J. 1978;1:896-7.
8. Veronesi U, Saccozzi R, Del Vecchio M, Banfi A, Clemente C, De Lena M, et al. Comparing radical mastectomy with quadrantectomy, axillary dissection, and radiotherapy in patients with small cancers of the breast. N Engl J Med. 1981; 305:6-11.

9. Butchart EG, Ashcroft T, Barnsley WC, Holden MP. Pleuropneumonectomy in the management of diffuse malignant mesothelioma of the pleura. Experience with 29 patients. Thorax. 1976;31:15-24.

10. Lee YC. Surgical resection of mesothelioma: an evidence-free practice. Lancet. 2014;384:1080-1.

11. Treasure T, Fiorentino F, Scarci M, Møller H, Utley M. Pulmonary metastasectomy for sarcoma: a systematic review of reported outcomes in the context of Thames Cancer Registry data. BMJ Open. 2012;2:e01736.

12. Bennett A. The cost of hope: a memoir. New York: Random House; 2012.

13. Ảberg T, Malmberg KA, Nilsson B, Nöu E. The effect of metastasectomy: fact or fiction? Ann Thorac Surg. 1980;30:378-84.

14. Åberg T. Selection mechanisms as major determinants of survival after pulmonary metastasectomy. Ann Thorac Surg. 1997;63:611-2.

15. Fiorentino F, Vasilakis C, Treasure T. Clinical reports of pulmonary metastasectomy for colorectal cancer: a citation network analysis. Br J Cancer. 2011;104:1085-97.

16. Simms L, Barraclough H, Govindan R. Biostatistics primer: what a clinician ought to know-prognostic and predictive factors. J Thorac Oncol. 2013;8: 808-13.

17. Utley M, Treasure T. Interpreting data from surgical follow-up studies: the role of modeling. J Thorac Oncol. 2010;5(6 Suppl 2):S200-2.

18. Treasure T, Miloševic M, Fiorentino F, Macbeth F. Pulmonary metastasectomy: what is the practice and where is the evidence for effectiveness? Thorax. 2014;69: 946-9.

19. Treasure T, Senan S. The need for randomized trials in mesothelioma: let's walk the talk. Oncologist. 2011;16:261-3. 